more than five years with patients with RA in a stationary setting. Results of the online survey demonstrate that the ranking of the impact of specific rehabilitation interventions did only marginally differ between the two person groups: Both groups ranked the importance of occupational and physical therapy the highest. Only the subjective importance of splints and assistive technologies was higher assessed by the general members of the ÖGR. Further, the ranking about the estimated impact of rehabilitation methods for patients with RA was very similar between the two person groups: The importance of rehabilitation for patients with functionality restrictions and for patients with RA in the first years of their disease was ranked the highest by both groups.

Conclusion: Results of the online survey demonstrate that ratings related to the impact of rehabilitation interventions for RA patients do only slightly differ between the investigated member groups of the ÖGR. Finally, the results indicate that rehabilitation methods for RA patients and rehabilitation related knowledge are well accepted and successfully transferred into disease management of patients with RA by professionals and experts in rheumatology in Austria.

Disclosure of Interests: Claudia Oppenauer: None declared, Elke Böttcher Grant/research support from: UCB,Roche, MSD, Speakers bureau: UCB, Pfizer, BMS,MSD,Roche,Amgen, Lilly, Gabriele Eberl: None declared, Albrecht Falkenbach: None declared, Winfried Habelsberger: None declared, Johannes Kirchheimer: None declared, Werner Kullich Shareholder of: Roche Stocks, Grant/ research support from: MedTec Company, Germany - MedizinTechnik, Erich Mur: None declared, Christa Oliveira-Sittenthaler: None declared, Georg Stummvoll Speakers bureau: Lilly, Roche, gsk, Christian Wiederer Consultant of: Firma Grünenthal, Thema Capsaicin, Dezember 2019, Harald Zeindler: None declared, Valerie Nell-Duxneuner Speakers bureau: MSD, Pfizer, Jansen, Abbvie, Lilly, Novartis

DOI: 10.1136/annrheumdis-2020-eular.2093

\section{THU0571 EFFICIENCY OF COMPLEX REHABILITATION PROGRAM IN PATIENTS WITH OSTEOARTHRITIS}

E. Orlova ${ }^{1} .{ }^{1}$ Moscow Centre for Research \& Practice in Medical Rehabilitation, Restorative and Sports Medicine, Moscow, Russian Federation

Background: Rehabilitation techniques and nonpharmacologic therapies help to relieve pain and improve functional status in patients with osteoarthritis $(O A)$ in addition to drug treatment [1-4].

Objectives: To evaluate the efficiency of 12-month complex rehabilitation program in patients with $O A$.

Methods: 50 patients with OA of hand, knee and ankle joints ( $76 \%$ females, age of 48 to 69 years, disease duration of 2 to 15 years) were included and randomized into 2 groups. All patients received non-steroidal anti-inflammatory drugs and chondroprotectors in standard doses. 26 study group patients underwent 12-months complex rehabilitation program: laser therapy of 12 to $15 \mathrm{~min}$ (infrared laser radiation, wavelength of 0,89 micrometers, pulse frequency of 1200 to $1500 \mathrm{~Hz}$ ) for hand, knee and ankle joints, 3 courses for 10 sessions with a mean interval of 3,3 months; 45-min dynamic exercises using gym apparatus Enraf-Nonius under the supervision of a trainer 3 times a week; 45-min exercises for hands 3 times a week; 45-min occupational therapy, 10 sessions; wrist, ankle and knee orthoses, education program ( 3 daily 90 -min studies); balance training on the COBS-platform 3 times a week. 24 patients received only drug therapy (control). Tender and swollen joint count, joint pain on 100-mm VAS, Lequesne index, WOMAC, hand grip strength, the average powers of knee extension and ankle flexion by EN-TreeM movement analysis, symmetry index (SI) and load distribution on the COBS-platform in the different modes were evaluated at baseline and at 12 months.

Results: After 12 month in the study group tender joint count decreased by $56,2 \%(p<0,01)$, swollen joint count - by $67,3 \%(p<0,01)$, pain on VAS - by $54,7 \%(p<0,01)$, Lequesne index - by 2,3 times $(p<0,01)$, WOMAC - by 1,8 times $(p<0,01)$. The grip strength of a more affected hand enhanced by $41,3 \%$ $(p<0,05)$, of a less affected - by $43,4 \%(p<0,05)$. The average extension power of a weaker knee increased by $57,3 \%(p<0,01)$, of a stronger - by $44,2 \%$ $(p<0,05)$. The average flexion power of a more affected ankle joint elevated by $34,9 \%(p<0,05)$, of a less affected - by $48,2 \%(p<0,05)$. The pressure on the COBS-platform of the extremity with more affected joint of the patients with OA of knee joints increased by $11,7 \%(p<0,05), S I-$ by $12,9 \%(p<0,05)$ in the mode «habitual stand». The load on the limb with more affected joint elevated by $13,2 \%(p<0,05), S I-$ by $25 \%(p<0,05)$ in the mode «get up and sit down». The pressure on the COBS-platform of the extremity with more affected joint of the patients with OA of ankle joints was enhanced by $14,3 \%(p<0,05), \mathrm{SI}$ - by $18,2 \%(p<0,05)$ in the mode «habitual stand». The load on the limb with more affected joint was elevated by $12,8 \%(p<0,05), \mathrm{SI}-$ by $20,1 \%(p<0,05)$ in the mode «tiptoe bounce (do not leave ground)». In the study group there were statistically significant differences from the control group in all parameters $(p<0,05)$.

Conclusion: 12-month complex rehabilitation program relieves pain, improves functional ability, power of motion, balance and load distribution in patients with OA.

References:

[1] Doi T, et al. Am J Phys Med Rehabil 2008;8(4):258-69.

[2] Zhang W, et al. Osteoarthritis Cartilage 2010;18:476-99.

[3] Hochberg M, et al. Arthritis Care \& Research 2012;64(4):465-74.

[4] Conaghan PG, et al. BMJ 2008;336:502-3.

Disclosure of Interests: None declared

DOI: 10.1136/annrheumdis-2020-eular.6381

\section{THU0572 THE ROLE OF PRESSURE PAIN THRESHOLD IN A REHABILITATIVE APPROACH TO ANALYZE PAIN PROCESSING MECHANISM IN HAND OSTEOARTHRITIS PATIENTS: A PILOT STUDY.}

P. Pedersini ${ }^{1}$, R. La Touche ${ }^{2}$, E. A. Sanchez Romero ${ }^{3}$, J. H. Villafañe ${ }^{1} .{ }^{1} I R C C S$ Fondazione Don Carlo Gnocchi, Milan, Italy; ${ }^{2}$ Centro Superior de Estudios Universitarios La Salle, Universidad Autónoma de Madrid, Madrid, Spain; ${ }^{3}$ Universidad Europea de Madrid, Madrid, Spain

Background: The hand pain experienced by patients with hand osteoarthritis $(\mathrm{OA})$ is often accompanied by hypersensitivity and sings of peripheral and central sensitization ${ }^{1}$. The European League Against Rheumatism (EULAR) published a systematic literature review that summarized the current non-pharmacological, pharmacological and surgical approaches for the management of hand $O A^{2}$. The identified review did not consider interventions that specifically targeted reducing pain sensitivity. A reliable method to assess the presence of hypersensitivity is the pressure pain threshold (PPT) ${ }^{3}$. During the rehabilitation management considering the pain mechanism involved could be an important factor to address more effective treatments ${ }^{4}$.

Objectives: The aim of the present study was to investigate the role of pain processing mechanism in patients with hand OA through PPT and using a specific functional Magnetic Resonance Imaging (fMRI).

Methods: 20 patients with hand OA and 20 healthy controls, aged 50 to 90 years, were recruited. Pressure pain threshold (PPT) was assessed bilaterally over the hand, on the C5-C6 zigoapophyseal joint, median, ulnar, radial nerves, and anterior tibial muscle by a blinded assessor respect to the condition of the subjects $^{3}$. In five participants for each group, PPT over the hand was assessed neurophysiologically by advanced modalities including functional MRI to analyze the pain mechanisms related to hand $O A^{5}$.

Results: The results showed that PPTs were significantly lower over the hand and the median, ulnar, radial nerves $(P<0.05)$, but not over the $\mathrm{C} 5-\mathrm{C} 6$ zigoapophyseal joint and anterior tibial $(P>0.05)$ in $O A$ patients as compared to healthy controls. Both groups demonstrated activation of the thalamus, frontal and somatosensory cortex area during PPT over the hand, although the total brain area activated in OA patients was greater than in control participants.

Conclusion: Patients with hand OA shown features of altered pain mechanism that were evident both in PPTs measures than using functional MRI. PPT is a useful marker in detecting pain sensitivity in hand OA and could be used in future pain studies to evaluate pain modulation strategies.

References:

[1] Villafañe $\mathrm{JH}$, Valdes $\mathrm{K}$, Pedersini P, Berjano P. Osteoarthritis: a call for research on central pain mechanism and personalized prevention strategies. Clin Rheumatol. August 2018

[2] Kroon FPB, Carmona L, Schoones JW, Kloppenburg M. Efficacy and safety of non-pharmacological, pharmacological and surgical treatment for hand osteoarthritis: a systematic literature review informing the 2018 update of the EULAR recommendations for the management of hand osteoarthritis. RMD Open. 2018;4(2):e000734.

[3] Pedersini P, Negrini S, Cantero-Tellez R, Bishop MD, Villafañe JH. Pressure algometry and palpation of the upper limb peripheral nervous system in subjects with hand osteoarthritis are repeatable and suggest central changes. $J$ Hand Ther. January 2019

[4] O'Leary H, Smart KM, Moloney NA, Blake C, Doody CM. Pain sensitization associated with nonresponse after physiotherapy in people with knee osteoarthritis. Pain. 2018;159(9):1877-1886.

[5] Sofat N, Smee C, Hermansson M, et al. Functional MRI demonstrates pain perception in hand osteoarthritis has features of central pain processing. $J$ Biomed Graph Comput. 2013;3(4)

Disclosure of Interests: None declared

DOI: 10.1136/annrheumdis-2020-eular.4143 